\title{
DO LIVRO DIDÁTICO FÍSICO AO IMATERIAL: O EMPURRÃO DA PANDEMIA
}

\author{
FROM PHYSICAL TEXTBOOK TO IMMATERIAL: THE PUSH OF PANDEMIC
}

Caio Kraide Gaeta1 ${ }^{1}$, Beatriz de Azevedo Blandy², Daniel Couto Gatti ${ }^{3}$

\section{RESUMO}

Este ensaio, de caráter exploratório, pretende situar a produção e uso educacional do conteúdo didático do ensino básico brasileiro durante e pós-pandemia, associando-as a políticas públicas que vêm sinalizando a mudança do conteúdo didático em livros físicos para o ambiente digital. Esse marco legal vem sendo implantado já há algum tempo, com resultados ainda pouco tangíveis. Porém no contexto da pandemia do Covid-19, evidenciou pontos críticos, mostrou lacunas estruturais e explicitou interesses. Aborda-se aqui o atual modelo de produção de conteúdo didático, relacionando-o ao PNLD (Programa Nacional do Livro Didático) e a passagem para plataformas de conteúdo. Aponta-se também as bases desejáveis para o desenvolvimento de um ensino híbrido em cenários futuros, nos termos de uma mudança paradigmática, que vai além do campo instrumental. Ao desenhar dinâmicas de criação de conteúdo, modelagem de currículos e avaliações, delineiam-se novos caminhos para o ensino e aprendizagem. Para traçar esse painel sobre o estado atual e possibilidades futuras dessa transformação, utilizamos marcos legais, referências bibliográficas, entrevistas e artigos de jornal.

PALAVRAS-CHAVE: Livro Didático. Ensino Básico. Pandemia. Tecnologia. Plataformas Digitais

\section{ABSTRACT}

This exploratory essay intends to situate the production and educational use of educational content in basic education in Brazil during and after the pandemic, associating them with public policies that have been signaling the change from educational content in physical books to the digital environment. This legal framework has been implemented for some time now, with results that are still intangible. However, in the context of the Covid-19 pandemic, it highlighted critical points, showed structural gaps and expressed interests. The current model of didactic content production is discussed here, relating it to the PNLD (National Textbook Program) and the transition to content platforms. It also points out the desirable bases for the development of a hybrid teaching in future scenarios, in terms of a paradigm shift that goes beyond the instrumental field. By designing dynamics of content creation, curriculum modeling and assessments, new paths for teaching and learning are outlined. To draw this panel about the current state and future possibilities of this transformation, we used legal frameworks, bibliographical references, interviews and newspaper articles.

KEYWORDS: Textbook. Basic Education. Pandemic. Technology. Digital Platforms

\section{RESUMEN}

Este ensayo exploratório pretende situar la producción y uso de contenidos educativos en la educación básica en Brasil durante y después de la pandemia, asociándolos con políticas públicas que vienen señalando el cambio de

1 Cientista Social graduado pela Universidade Estadual Paulista (FFC-UNESP). Mestrando em Tecnologias da Inteligência e Design Digital (PUC-SP), investiga as novas transformações tecnológicas e seus desdobramentos para o trabalho e educação no Brasil. Áreas de interesse: Sociologia do Trabalho; Transformação Digital; Educação profissional; Futuro do trabalho;

2 PUC-SP (Pontifícia Universidade Católica de São Paulo)

3 PUC-SP (Pontifícia Universidade Católica de São Paulo) 
contenidos educativos en libros físicos al entorno digital. Este marco legal se viene implementando desde hace algún tiempo, con resultados que aún son intangibles. Sin embargo, en el contexto de la pandemia Covid-19, destacó puntos críticos, mostró brechas estructurales y expresó intereses. Aquí se analiza el modelo actual de producción de contenido didáctico, relacionándolo con el PNLD (Programa Nacional de Libros de Texto) y la transición a las plataformas de contenido. También señala las bases deseables para el desarrollo de una enseñanza híbrida en escenarios futuros, en términos de un cambio de paradigma que vaya más allá del campo instrumental. Al diseñar dinámicas de creación de contenido, modelado y evaluaciones curriculares, se perfilan nuevos caminos para la enseñanza y el aprendizaje. Para elaborar este panel sobre el estado actual y las posibilidades futuras de esta transformación, se utilizaron marcos legales, referencias bibliográficas, entrevistas y artículos periodísticos.

PALABRAS CLAVE: Libro de texto. Educación básica. Pandemia. Tecnologia. Plataformas digitales 


\section{INTRODUÇÃO}

Neste ensaio, de caráter exploratório, partiu-se da análise do impacto da pandemia na transposição de estratégias didáticas e conteúdos baseados em aulas presenciais e livros físicos para ambientes virtuais. Nesse sentido, realizou-se uma pesquisa com bases de dados (Scielo/ Web Science e revistas de educação e tecnologia). Utilizamos palavras chaves como educação, ensino básico, tecnologia, ensino remoto, sistemas de ensino, Covid-19, pandemia. De um conjunto de 35 artigos que apontavam temas convergentes, selecionou-se nove artigos que narram experiências sobre essa transformação, refletindo sobre esses aspectos.

O mesmo processo repetiu-se a partir de palavras-chave como livro didático, PNLD, livro digital, mostrando uma outra faceta do mesmo tema. Nesse caso, com referências muito centradas no caso brasileiro e com foco nos riscos e vantagens da transposição, uma abordagem mais técnica do que importaria essa transformação.

Em função da atualidade do tema e da impossibilidade de procurar referências acadêmicas sobre o estado atual da passagem do conteúdo didático físico para o meio digital, fizemos duas entrevistas com profissionais que tem um longo percurso na área. Além de articular a emergência da implantação do ensino remoto na pandemia com o tempo e as exigências do marco legal que define os conteúdos didáticos usados do Ensino, buscamos categorizar os problemas e vantagens dessa passagem, de maneira que pudéssemos antever parâmetros para uma implantação mais lenta e segura.

Nos parágrafos seguintes, intenciona-se, através de relatos de várias experiências unidas pelo contexto educacional na pandemia, agrupar pontos comuns, criando um mapa do que essa situação de exceção revelou sobre esse processo, suas vantagens e lacunas.

\section{UM CONTEXTO DE EXCEÇÃO E SUAS LIÇÕES: O EMPURRÃO DA PANDEMIA}

O avanço mundial da Covid-19 gerou impactos em todas as áreas da nossa sociedade, seja transformando o cotidiano de milhares de pessoas, como trazendo demandas emergenciais e em áreas essenciais como a saúde, a economia e a educação. No auge do período de isolamento, um levantamento da Unicef mostrou que ao menos 463 milhões de estudantes ficaram sem escola em mais de 190 países. Mais de $90 \%$ dos ministérios de educação forneceram políticas de ensino remoto e inclusão digital; porém, ao menos $31 \%$ dos estudantes no mundo todo não puderam ter acesso a esses programas, em razão da falta de requisitos básicos para acesso. (UNICEF, 2020). A partir desses dados, é possível integrar o Brasil num mapa da desigualdade mundial. Se criarmos um foco na rede pública de ensino, vemos que $39 \%$ dos alunos não têm computador ou tablet, enquanto apenas $9 \%$ dos alunos das escolas particulares não possuem esses recursos (CETIC, 2019). Essa diferença de condições modifica e esclarece as narrativas sobre essa passagem de aulas presenciais para canais virtuais. Ao mesmo tempo que aponta caminhos para o uso de tecnologias virtuais em todo o ensino básico, a interrupção das aulas presenciais evidenciou também a enorme dificuldade para incorporar essas tecnologias ao ensino oferecido na rede pública e o impedimento estrutural e sistêmico de uma significativa parte da população de crianças e adolescentes brasileiros de usufruir desses avanços (ALMEIDA, 2020).

Com a elevação tecnológica mundial em diversos contextos sociais, o espaço escolar passou a adotar os recursos tecnológicos como estratégia didática muito antes do cenário pandêmico emergente. Assim, durante a pandemia, muitas barreiras foram rompidas entre o ensino físico e virtual, criando possibilidades de uma educação híbrida. Essa nova linguagem, como dizem os autores Benedito e Castro Filho (2020), revisitada a partir de relatos e experiências vividas durante a pandemia é um dos temas deste ensaio, que pretende identificar áreas de avanço tecnológico, práticas em transformação e pontos de atenção nesta mudança, alinhando o que pudemos melhor compreender durante este confinamento.

Sem dúvida, a falta de infraestrutura de acesso à internet e as condições oferecidas pelas escolas para uso de tecnologia foi um dos maiores obstáculos para o sucesso da implementação, um problema comum e estrutural ao território brasileiro. Por exemplo, na região Nordeste brasileira, um faltam computadores para todos os alunos, o 
acesso a internet é limitado ao corpo docente, "e, na maioria das vezes, a escola não dispõe deste ambiente" (BENEDITO E CASTRO FILHO, 2020). Já no estado do Paraná, um dos mais ricos do país, onde $67,2 \%$ da população tinha acesso à internet (IBGE, 2018), o mesmo censo indicou que em $85,86 \%$ dos domicílios, havia pelo menos um celular e esse era o equipamento mais usado para acessar à internet em $93,5 \%$ das casas. Ou seja, ora não dispõe do acesso, ora não dispõe dos equipamentos adequados para atender a demanda das crianças e jovens para o ensino remoto (GOMES et al, 2020). Situações similares são relatadas num estudo realizado no Equador (RAD CAMAYD E ESPINOZA FREIRE, 2021) e na implementação do programa Aprende en Casa, no México, onde as condições do meio rural obrigaram os professores a modificarem estratégias educacionais, oferecendo apoios específicos aos alunos, em diferentes de condições de ensino em relação ao contexto urbano (PEÑUELAS, GONZÁLEZ, PIERRA,2020).

As dificuldades enfrentadas pelos alunos das periferias das cidades e dos que moram no campo, evidenciam que os prejuizos se acumulam sobre as camadas mais pobres da população. Ou seja, as condições necessárias para o desenvolvimento tecnológico não ocorrem de forma homogênea, mas estão subordinadas a uma lógica seletiva de distribuição de renda e de interesses de capitais financeiros. Essa condição de desigualdade, na mesma cidade ou em regiões inteiras mostrou-se imediatamente, a partir da necessidade de um maior aporte tecnológico para organizar um ensino remoto. A despeito do caráter ecumênico da crise sanitária que se alastrou pelo mundo e de muitas soluções criativas para superar essa lacuna, ativar um nível mais alto de demanda tecnológica, revelou as precariedades dessa implantação do livro digital, que como vimos, já estava em curso.

Nessas condições, soluções como a adotada pela Secretaria da Educação do Ceará, são um exemplo do que aconteceu em muitas das experiências relatadas. Cada unidade escolar criou um plano de ensino, com atividades domiciliares e o uso do livro didático físico foi apontado como principal ferramenta para as aulas remotas. Além disso, foram disponibilizadas plataformas digitais como o Aluno Online, Professor Online, Google Classroom, utilizadas para o envio e recebimento de atividades, correções e trocas de informação. As interações entre professores e alunos foram garantidas, em parte, pelo uso de plataformas como o WhatsApp, o Zoom, o Teams e o Google Meet. Um ganho significativo foi a rapidez com que se conectaram professores e alunos, criando redes de circulação de informação e conteúdo, com bastante autonomia e efetividade, porém com tecnologias pouco adaptadas ao manejo, apresentação e interação com conteúdo didático (BENEDITO; CASTRO FILHO, 2020).

Ou seja, essa experiência de implantação emergencial do ensino a distância em escala e de modo desigual, segundo renda e região, contribuiu para reforçar o caixa e o poder das grandes corporações de tecnologia como Google e Microsoft, que abocanharam fatias graúdas do mercado de educação. Além disso, vinculados à venda de plataformas virtuais de mídia, há pacotes completos com modelo de aula, currículo trabalhado e avaliação dos resultados (NEVES, 2020). O mercado de sistemas de ensino se beneficiou desse movimento, tanto no caso da rede pública, como da rede privada.

A pandemia também tornou mais aquecido o mercado de fusões e aquisições em educação, ao colocar pressão em algumas redes de ensino por um lado e abrir oportunidades para consolidação daqueles grupos que já eram mais avançados no ensino a distância (MARINELLI et al, 2020, on-line).

Uma pesquisa da Associação Brasileira de Ensino a Distância (ABED) foi realizada no Estado de São Paulo, entre os dias 25 de maio e 9 de junho de 2020. Esta amostragem contou com 206 escolas privadas de 74 municípios, das quais 187 oferecem Educação Infantil (EI), 178 oferecem Ensino Fundamental I, 147 oferecem Ensino Fundamental II e 111 oferecem Ensino Médio. Esse conjunto de escolas majoritariamente selecionou e contratou ferramentas de ensino remoto e conteúdos gratuitos e pagos. Os professores de Ensino Fundamental II e Ensino Médio receberam mais apoio sobre o uso das ferramentas do que os demais e um pouco mais de apoio financeiro para investir em tecnologia ( $41 \%$ das escolas adotaram essa prática no EFII e EM). Entre 48\% (Educação Infantil) e $58 \%$ (Ensino Médio) das escolas contrataram ferramentas tecnológicas para dar apoio às aulas e entre $24 \%$ (Educação Infantil) e $41 \%$ (Ensino Médio) contrataram conteúdos neste período. Muitas escolas adotaram conteúdos fer- 
ramentas e conteúdos gratuitos, mais especificamente, 46\% (Ensino Fundamental II) e 56\% (Ensino Fundamental I) (ABED, 2020).

Este investimento das escolas privadas, elevou a rentabilidade de alguns grupos educacionais e exigiu uma guinada tecnológica de outros. Mas, somente $40 \%$ das instituições desenvolveu novas metodologias para este momento. As escolas deram um jeito e mantiveram as atividades letivas e os alunos envolvidos com professores e conteúdos, sem uma mobilização em torno da adoção de tecnologias digitais.

Wilson Troque, ex-coordenador geral dos Programas do Livro do Fundo Nacional de Desenvolvimento da Educação (FNDE), em entrevista para o presente artigo, traz uma perspectiva convergente. Segundo o entrevistado, que agora atua na Fundação para o Desenvolvimento da Educação (FDE) em São Paulo, as políticas que aparecem sem entender o entorno não têm possibilidade de êxito nenhum. "Quando saíram os tablets, ipads, muitas escolas tinham para mostrar, mas não havia nem conteúdo nessa época para isso. A tecnologia é complementar, ainda existem diversas coisas mais importantes do que a própria tecnologia." (TROQUE, 2021, n.p.). A iniciativa de se fornecer um tablet para um estudante, por exemplo, não pode ser feita sem considerar a viabilidade de utilização em regiões sem o devido suporte. Segundo Troque, "As escolas precisam parar de fazer da tecnologia um marketing e fazer, efetivamente, uma mudança tecnológica”.

O segundo aspecto mais citado é a formação e aperfeiçoamento docente para o ambiente virtual e o manuseio dos recursos tecnológicos da comunicação, o que afeta significativamente no modo como o professor utiliza a seu favor essas ferramentas (BENEDITO; CASTRO FILHO 2020). Os autores Camayd e Freire (2021), que realizaram uma pesquisa com docentes no Equador, detalham aspectos desse ponto crítico.

[...] são as habilidades tecnológicas, habilidades para o desenvolvimento de mídias digitais de ensino (apresentações, software etc.); domínio de metodologias de uso de recursos tecnológicos; a adaptação do programa e das atividades curriculares; o tempo disponível para ajudar os alunos e habilidades de gerenciamento de informações.

Ou seja, a formação tecnológica dos professores foi e será um aspecto chave para a implantação de conteúdos didáticos em meios imateriais. Observa-se que, nessa situação emergente, a obrigatoriedade do uso de tecnologias contribuiu efetivamente para experimentações e aquisições de novas habilidades. Criaram-se redes de trocas, formações pontuais e reforçou-se a proximidade com alunos e familiares, através de formas não presenciais. Um dos ganhos desse tempo de pandemia é oferecer e familiarizar professores com um novo suporte, bem como, desenvolver, construir, interagir e socializar conhecimentos virtualmente, a partir da troca de experiências de docentes em todos os níveis acadêmicos (SALAZAR e VALLEJOS, 2021).

Do ponto de vista do alunado, as consequências dessa implantação emergencial só serão conhecidas no médio prazo. Porém, uma pesquisa feita com alunos pela ABED sobre a qualidade do ensino remoto na pandemia mostra que a qualidade é reprovada por $72,6 \%$ dos alunos. O estudo ouviu a opinião de mais de 5,5 mil estudantes, professores e responsáveis entre 24 de agosto e 15 de setembro de 2020. Segundo o levantamento, do total de entrevistados, só $20 \%$ afirmaram que a qualidade se manteve e apenas $7 \%$ notaram uma melhora na qualidade do ensino remoto, comparado com a modalidade presencial. Os estudantes relatam que, entre os principais obstáculos ao ensino virtual são a dificuldade em estabelecer e organizar a rotina diária e o fato de as escolas mandarem muitos materiais em curto espaço de tempo. E a pedra no sapato é a qualidade da internet em todo território nacional. Nessa pesquisa, mais de $92 \%$ dos entrevistados são estudantes de escolas públicas, sendo $76,85 \%$ alunos do ensino médio. O uso de smartphone foi o principal meio de acesso para $91 \%$ dos jovens (ABED, 2020).

Assim, como essa pesquisa da ABED aponta, o terceiro e mais citado aspecto é a necessidade de formação para o trabalho autônomo, de organizar-se para estudar e da responsabilidade sobre o estudo e suas tarefas. Há, sem dúvida, o desconhecimento de ferramentas digitais e estratégias de pesquisa, mas a questão de fundo é um conjunto de atitudes, essenciais ao trabalho remoto. O papel das famílias foi outro ponto crucial, que contribui positivamente para essa passagem, como também sobrecarregou pais ou deixou crianças em situações difíceis no 
momento do estudo (GOMES et al, 2020; RAD CAMAYD E ESPINOZA FREIRE, 2021; SALAZAR e VALLEJOS, 2021; PEÑUELAS, GONZÁLEZ, PIERRA,2020).

Lvari, Sharma E Olkkonen (2020), pesquisadores finlandeses, narram uma adaptação suave ao confinamento e ao ensino remoto. Porém tocam num tema central para o foco da transformação. "Sustentamos que a exclusão digital não se trata apenas de acesso ou uso de tecnologia digital, mas sobre ser capaz de integrar a tecnologia digital em práticas sociais significativas e obter benefícios dessa transformação".

Um aspecto que mereceu atenção do sistema educacional finlandês foi a questão do tempo, que levaram a mudanças na organização de aulas e da grade curricular. É sabido que a capacidade de concentração no meio virtual é menor do que nas aulas presenciais, apesar de variar muito nas faixas etárias que compõem o ensino básico. Relatam que, ao invés de manter o mesmo modelo de aulas presenciais, se organizaram intervalos para trabalho individual acompanhado, fizeram junções de turmas e uniram professores interagindo durante as aulas. Sem dúvida, estas estratégias devem ter sido colocadas em prática no mundo todo, mas foram bastante valorizadas no sistema finlandês.

A partir do papel/relevante da Finlândia na transformação tecnológica em escala mundial, os autores Lvari, Sharma e Olkkonen (2020) reforçam que há uma oportunidade em avançar na transformação digital na educação, da mesma forma como fizeram na indústria e outros setores.

[…] Poderíamos capacitar os professores, as escolas e a formação de professores para atuar como líderes da transformação digital da educação. Futuros educadores devem receber habilidades e competências para compreender, refletir, planejar e liderar o processo pelo qual eles geram respostas estratégicas por meio de tecnologias digitais, bem como gerenciar as mudanças estruturais e barreiras organizacionais que surgem (Lvari, Sharma e Olkkonen, 2020, p.5).

Ou seja, os pesquisadores finlandeses acentuam a necessidade de mudanças na organização do tempo, as oportunidades de transversalidade e de flexibilidade para o aproveitamento dos saberes de cada professor. Mas, principalmente, reforçam a necessidade de criar uma reflexividade, compreensão e participação de todos os envolvidos no processo para que possam ser protagonistas e tomar decisões de como gerar respostas para as questões da implantação de tecnologias digitais. Assim o quarto e último aspecto, são as transformações em toda a cadeia de produção do conteúdo didático; as possibilidades de autoria, interação e troca dos envolvidos e as mudanças que se produzem nas práticas, didáticas e modulações curriculares, a partir da sua implantação.

Através deste painel, pode-se afirmar que a pandemia trouxe um palpável avanço para a transformação digital, um empurrão como está no título deste ensaio. Porém, expôs pontos críticos com a mesma intensidade. Desde a falta de estrutura e desigualdade de condições para um acesso seguro dos alunos ao meio digital, como a desmobilização do alunado diante dessa dificuldade. As adaptações apressadas de livros físicos para um ensino sem caderno e sem carteira mostraram também um significativo desconhecimento de educadores e editores de conteúdo didático sobre essa passagem. E, sem dúvida, ficou evidente o despreparo de alunos e professores em estudar e ensinar a sós, num ambiente desconhecido, precário e imaterial.

Ao planejar o retorno às aulas presencias, pode-se dizer que sabemos que as mídias tecnológicas podem ser utilizadas de modo tão passivo quanto as aulas tradicionais, trazendo cautela na instalação de um ensino híbrido. O que parece viável é integrar mídias e mediações motivadoras ao trabalho pedagógico. Outra contribuição importante nas reflexões de Gatti (2020) sobre o que experimentamos nesse período de confinamento é que ao reproduzir tão rapidamente conteúdos e currículos num outro suporte, formou-se algum consenso que o modelo escolar baseado em visões imediatistas e competitivas pede mudanças. "Tudo nos chama a repensar a educação fragmentária, de caráter apenas cognitivo, sem sentido para muitos jovens e adolescentes. Imbricar valores ao domínio de conhecimentos é o vetor saudável a preservar para novos tempos" (GATTI, 2020).

A partir deste recorte que se propõe a investigar ganhos e lacunas do que aconteceu durante o empurrão tecnológico dado pela pandemia, nossa intenção foi criar uma base para examinar o atual estado da implantação do 
uso intensivo de tecnologia no Ensino Básico. E apontar aspectos que possam orientar soluções desejáveis à luz dessa experiência. Na próxima seção, vamos examinar o Programa Nacional do Livro Didático (PNLD) que define as bases legais dessa passagem para o ensino público. Uma rede que abarca $81 \%$ das matrículas dessa ampla faixa etária e forma quase um quarto de toda a população brasileira.

\section{PNLD: O MARCO LEGAL E PÚBLICO DA PASSAGEM DE MEIOS FÍSICOS PARA VIRTUAIS}

O Programa Nacional do Livro Didático (PNLD) é o mais antigo dos programas do Brasil para distribuição de obras didáticas a estudantes da rede pública de ensino (BRASIL, 2017a). Teve início em 1937, com outro nome, e foi historicamente adaptado ao longo dos mais de oitenta anos de existência. Atualmente, o programa se destina à educação básica e a alunos da educação infantil.

Por se tratar de um programa de abrangência nacional e por fomentar uma produção e distribuição material de grande escala, o PNLD surte efeito sobre o campo econômico brasileiro, especificamente no que se refere ao mercado editorial e a indústria de papel. Para atender a demanda do programa, estabelece e gerencia essa relação entre o setor público e o privado, expandindo a escala de atuação de editoras de livros e abrindo espaço para novas empresas e frentes de atuação.

\footnotetext{
O estabelecimento de parcerias com o setor público para a produção de grandes tiragens de livros didáticos permitia o acúmulo de um grande capital econômico nas empresas, comparável à edição de livros de literatura de autores renomados como Jorge Amado e Érico Veríssimo. A perspectiva de lucros com os didáticos impulsionou, inclusive, a criação de novas editoras e o investimento no setor por parte de editoras consagradas em outras áreas. (VAHL; PERES, 2017, p. 582).
}

O PNLD demarca também uma disputa editorial, guiada pelo propósito de captar o investimento público necessário. Ainda que exista grande demanda por parte do governo e muitas editoras se mostrem capazes de produzir os materiais do programa, o investimento financeiro não é necessariamente distribuído de forma proporcional. Como demonstra o estudo de Vahl e Peres (2016) sobre tal disputa durante a fase anterior do programa (ainda sob o nome de Plidef), das 36 editoras inscritas no programa, somente nove publicaram mais de $70 \%$ das obras. Neste caso, estratégias diversas são adotadas para obter o direito de publicação, dada a relevância do investimento financeiro feito pelo governo do Estado. Atualmente, a participação do governo na dinâmica econômica do mercado editorial brasileiro ainda é expressiva, especialmente em razão do próprio PNLD.

A partir de informações disponibilizadas pelo governo brasileiro em 2018, que tomam como base pesquisas publicadas pelo Banco Nacional de Desenvolvimento Econômico (BNDES), temos importantes fatores relacionados ao direcionamento do governo federal quando tratando de livros didáticos. Os dados a seguir estão disponíveis no portal do BNDES:

1) Quase $50 \%$ de todos os livros (exemplares) vendidos em 2016 foram didáticos. [...] 2) Dos mais de 200
milhões de livros didáticos produzidos naquele ano, 147 milhões foram vendidos por meio do Programa
Nacional do Livro Didático (PNLD). [...] 5) O Governo Federal é o maior consumidor individual de livros no
Brasil, por meio do PNLD e também do Programa Nacional Biblioteca na Escola (PNBE). (BRASIL, 2018)

Esses dados indicam a participação expressiva que tem o governo brasileiro para o consumo geral de livros no Brasil. No caso de livros didáticos, a maior parte das aquisições é feita por meio do PNLD. Neste mesmo conteúdo, o governo também aponta que "o faturamento com o livro didático digital foi 0,09\% do faturamento total do segmento em 2016" (BRASIL, 2018), segundo o Censo do Livro Digital, publicado pelo Sindicato Nacional dos Editores de Livros (SNEL).

O Censo do Livro Digital, mencionado pelo governo, traz também a informação acerca das obras em geral, 
para além dos livros didáticos. Quando comparadas, temos que o consumo de livros digitais feitos no Brasil representam uma fração significantemente menor, sendo menos de $4 \%$ do faturamento obtidos em obras gerais:

Tabela 1 - Faturamento $(R \$)$ em 2016

\begin{tabular}{l|cccc}
\multicolumn{5}{c}{ FA TURAMENTO (R\$) EM 2016} \\
Fisico & Digital & Total & \% Digital \\
\hline Didáticos & $1.436 .755 .942,45$ & $1.268 .865,70$ & $1.438 .024 .808,15$ & 0,09 \\
\hline Obras gerais & $1.023 .569 .104,47$ & $24.971 .699,38$ & $1.048 .540 .803,85$ & 2,38 \\
\hline
\end{tabular}

Fonte: Elaborado a partir do Censo do Livro Digital (SNEL, 2018)

Ainda que a produção de livros didáticos seja estimulada pelo PNLD e que $37 \%$ das editoras do Brasil, neste período, já trabalhassem com a produção e comercialização de e-books (SNEL, 2017), a categoria de livros didáticos digitais manteve-se dentro do campo de $\mathrm{R} \$ 1,2$ milhão de faturamento, enquanto o livro impresso ultrapassou a arrecadação de 1,4 bilhão.

Dentro desse contexto, a pesquisa publicada pelo BNDES sobre tendências da era digital na cadeia produtiva do livro (MELLO et al. 2016) aponta que há uma série de desafios a serem superados para que novas tecnologias digitais possam ser mais rapidamente implantadas. Para isso, "O governo, por meio, principalmente, de seu poder de compra, teria condições de assumir esse papel, incentivar o desenvolvimento e o uso gradual dessas tecnologias" (MELLO et al. 2016, p.77). Neste sentido, pode-se dizer que o PNLD 2023 representa um marco no projeto de incentivo nacional à difusão de novas tecnologias.

\section{O PNLD 2023}

Por meio do PNLD, o FNDE (Fundo Nacional de Desenvolvimento da Educação) executa "um conjunto de ações voltadas para a distribuição de obras didáticas, pedagógicas e literárias, entre outros materiais de apoio à prática educativa, destinados aos alunos e professores das escolas públicas de educação básica do País." (BRASIL, 2017b, on-line).

O edital 01/2021 - CGPLI, que convoca a inscrição e a avaliação das obras didáticas para o programa de 2023, conduz o programa por um novo caminho, trazendo especificações para a produção de obras digitais. Junto ao edital, a página do programa disponibiliza também um recomendações sobre oferta de livros digitais para o programa (RNP, 2021a), feita pela RNP (Rede Nacional de Ensino e Pesquisa) e um descritivo de tecnologias (RNP, 2021b).

Uma particularidade deste edital de convocação está na requisição de que todos os livros inscritos no programa, assim como o manual do professor, devem ter também versões digitais, especificamente no padrão HTML5, reproduzindo o conteúdo dos materiais. Segundo o descritivo de tecnologias da RNP (2021b), a escolha foi definida em vista de critérios fundamentais como a acessibilidade, interoperabilidade, utilização do mercado e possibilidade de tecnologias de apoio. Dentro do padrão HTML5, existem formatos diversos que podem ser utilizados, como o EPUB3, muito comum para a publicação de e-books.

Neste relatório recomendatório há diversas orientações, que levam em consideração o perfil do usuário brasileiro e particularidades locais. Dentre essas informações, temos que menos de $45 \%$ das editoras brasileiras (respondentes na pesquisa) estão em nível tecnológico adequado ou avançado para atender os requisitos de fornecimento de livros digitais ao PNLD 2023 (RNP, 2021a).

Outro parâmetro relevante deste edital está relacionado à Lei Brasileira de Inclusão da Pessoa com Deficiência - Lei n 13.146/2015. Segundo a orientação do governo, é preciso que os editores forneçam também obras no formato acessível, e que o livro digital acessível seja o mesmo livro que será distribuído para os estudantes sem 
deficiência (BRASIL, 2021). Com isso, está colocado o desafio para a elaboração do formato digital, que por lei, não aceitará recursos que estejam fora dos padrões de acessibilidade,

Em vista da relevância histórica do PNLD para o mercado editorial brasileiro, assim como da exigência do PNLD 2023 para a produção de livros no formato digital, temos uma aproximação do governo brasileiro do papel de catalisador de difusão das tecnologias digitais, como apresentado por Mello (2016).

Por outro lado, o mesmo PNLD 2023, o faz com uma visão estrita, onde todo livro impresso deve ter uma versão digital exatamente igual. Assim cria-se nesta fase de implantação, um severo desajuste entre as potencialidades do livro digital, como o uso de mídias e links e os materiais didáticos físicos, sua organização de conteúdos e práticas. Detalhamos um pouco mais esse tema na próxima seção.

Segundo Troque, essa aproximação não se deu por consenso. Conforme relata o entrevistado, que esteve em reuniões acerca do direcionamento do PNLD 2023, as propostas de utilização do formato digital encontraram grande resistência. Primeiramente, por parte das editoras, interessadas no formato tradicional da impressão de didáticos. Também houve resistência por parte das empresas envolvidas neste processo de transformação. Pelos ministérios, tornou-se claro um não entendimento das razões e propósitos dessa proposta. "Cada um fica defendendo seus interesses e olham pouco para o que realmente importa" (TROQUE, 2021, n.p.). Como consequência, temos um processo de inclusão digital ainda primário, sem chance de se completar em curto prazo, apesar do impulso possibilitado pelo contexto do ensino remoto.

\section{PROCESSOS DE PRODUÇÃO E DE LEITURA}

As pesquisas que embasam a publicação do BNDE, tomam com base anos anteriores a 2018, principalmente até 2016. Neste intervalo, o cenário editorial digital teve mudanças significativas. A SNEL, instituição responsável pelo Censo do Livro Digital —, em parceria com a Nielsen Books - passou a realizar uma pesquisa anual sobre o Conteúdo Digital do Setor Editorial Brasileiro. No estudo de 2019, vemos que o crescimento nominal do faturamento com conteúdo digital foi de $140 \%^{1}$ em 3 anos (NIELSEN, 2020a), mostrando o potencial de crescimento desta área.

Por outro lado, a presença do livro físico em sistemas de ensino é bastante familiar: o formato de livro impresso que não mudou estruturalmente no decorrer do último século. Porém, no ano de 2019, representou um desembolso R $\$ 1.6$ bilhão para o Governo brasileiro. (NIELSEN, 2020b). Na performance comparativa entre categorias, os livros didáticos produzidos ocupam mais de 47\% de todo volume de livros impressos em 2019 (NIELSEN, 2020b). Tendo em vista a expressiva participação dos didáticos para a produção editorial do Brasil e a proposta apresentada pelo edital do PNLD 2023, alguns pontos acerca da produção dos livros em formatos digitais devem ser considerados.

${ }^{1}$ Quando considerada a inflação do período, o crescimento desse faturamento é de $115 \%$. (SNEL, 2020) 
Figura 1 - Cadeia produtiva do livro no Brasil

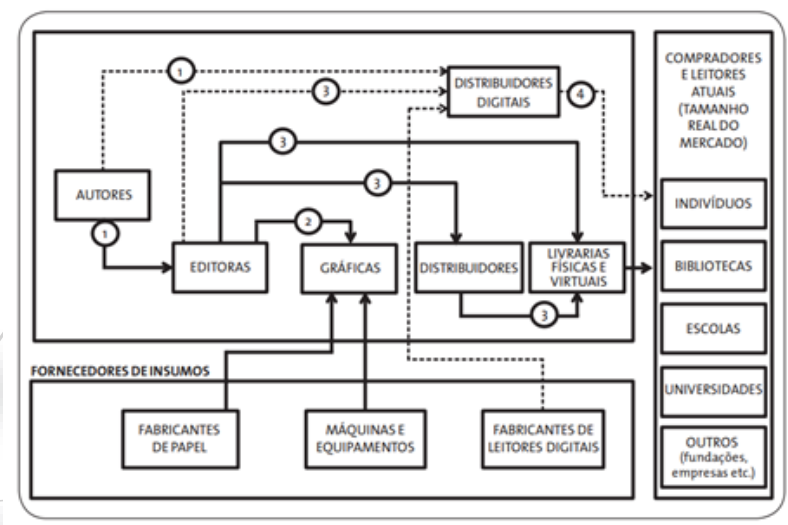

Fonte: Mello et al. (2016).

A figura 1 representa a cadeia produtiva de livros digitais e impressos no Brasil. Segundo o esquema, a editora é responsável por encaminhar os processos depois da relação com o autor, quando se trata de livros físicos, para as próximas etapas com gráficas, distribuidores e livrarias físicas e virtuais. Para a forma de distribuição digital, no entanto, há também a possibilidade do self-publishing. Por este caminho (ver pontilhado), em vista da autonomia concedida pelo meio digital, os autores podem cuidar também da editoração e comercialização, sendo então responsáveis por todas as etapas do processo (MELLO et al., 2016). Algo ainda a ser entendido nesse novo modo de produção, tanto em termos de alcance, quanto na criação de vantagens para o autor ou ameaças para grandes editoras.

Porém, o grande mercado de e-books, lida com um cenário que não é o do self-publishing, mas o da replicação de materiais já produzidos por editoras para o meio virtual. Ou seja, temos livros que são projetados para o meio impresso, e posteriormente veiculados na internet para leitores de e-books ou demais dispositivos. Em geral, os livros digitalizados são oferecidos em formatos como, ePUB PDF ou MOBI, que muito se assemelham com o livro impresso, adaptados ao tamanho da tela para melhores condições de leitura.

Os formatos convencionalmente utilizados para livros digitalizados permitem poucas dinâmicas de interação. Na maior parte, a possibilidade de cliques se resume à escolha de um capítulo no índice, à demarcação de alguma parte com ferramentas de destaque ou criação de caixas de anotação. São recursos úteis à navegação, e seguem fazendo referência a práticas adotadas no meio físico, como a utilização de marca páginas, canetas marca-texto ou anotações de fichamento. Entretanto, o ambiente virtual possibilita relações mais complexas do que as oferecidas e têm contribuído para a proposição de novas formas de interação entre o estudante e conteúdo.

Quando explorados a partir do seu formato, os livros digitais podem incorporar recursos bastante complexos. Com ferramentas de questões, o leitor pode responder a testes durante a atividade de leitura. Essa atividade pode gerar um valor em nota, por exemplo, para que ele avalie quais partes do conteúdo estão sendo bem assimiladas. Outra viabilidade é a de incorporação de formatos para além do texto escrito, como a presença de arquivos de áudio e vídeo. No formato HTML5, por exemplo, a exposição de um texto pode ser facilmente intercalada com trechos de documentários, músicas ou até mesmo pequenos jogos relacionados ao conteúdo tratado.

Como os impressos editoriais não são projetados para interação com recursos disponíveis digitais, a linguagem se resume à forma convencional de livros impressos. Um aspecto problemático para atrair e interagir com a cultura dos nativos digitais (PRENSKY, 2010).

Conforme apresentam Caldin e Blattmann em seu estudo sobre letramento digital e e-books interativos para crianças, é possível conferir que a presença de livros digitais interativos - não somente digitalizados, mas ricos de recursos dinâmicos - é uma realidade até mesmo para as crianças. Para famílias economicamente favorecidas, "o letramento digital pode acontecer até mesmo antes do letramento tradicional." (CALDIN; BLATTMANN, 2020, p. 694). Por mais que a narrativa do livro impresso continue presente, as autoras ressaltam a importância de se com- 
preender o tipo de leitura feita por novas gerações:

Muito embora o impresso continue a fazer parte das vivências do ser humano, no século XXI é cada vez mais precoce o letramento digital. Cabe aos adultos (pais, professores, bibliotecários) adentrarem no universo lúdico da hipermídia, conhecerem autores e obras e disponibilizarem, cada vez mais, e-books interativos para crianças. (CALDIN; BLATTMANN, 2020, p. 698)

Para lidar com este tipo de leitura e interação com o estudante, não basta que as páginas sejam simplesmente disponibilizadas como uma réplica do livro impresso. Neste contexto, surgem também empresas dispostas a prestar o serviço de adaptação de livros impressos para formatos digitais dinâmicos, que considerem também o seu propósito educacional.

Como exemplo de iniciativa da adaptação de livros tradicionais para o formato digital, a empresa espanhola Blink Learning oferece o serviço específico de converter livros para o formato HTML5. A proposta é feita em parceria com editoras tradicionais, que solicitam a adaptação de títulos projetados na forma impressa para o modelo digital. Atualmente, essa empresa possui parceria com grandes grupos, como Pearson, Oxford Universisty Press e Cambridge University Press (BLINKLEARNING, 2021), e oferece sua base de conteúdo digital para escolas em diversos países por meio de sua plataforma.

Nesse processo de adaptação, baseia-se na obra original para criar um formato digital do livro, compatível com dispositivos móveis de forma responsiva (adaptando o layout de acordo com o meio utilizado). No formato HTML5, também podem ser inseridas questões ao longo do texto, para que o leitor exercite o que aprendeu. Uma vez desenhado o projeto do livro digital, a empresa o submete à aprovação da editora, que pode validar a publicação ou requerer ajustes (BLINKLEARNING, 2020).

Ainda assim, o ponto de partida dessa atividade é o livro impresso, que nem sempre apresenta propostas de interação com o seu leitor. É importante demarcar aqui uma diferenciação entre um livro que se tornou digital para um livro que é projetado desde o início para o formato digital, por mais que exista esse trabalho de adequação. Para que um livro seja pensado desde o início no formato digital, pressupõe-se que o próprio autor já conheça as possibilidades oferecidas pelo ambiente virtual. Especificamente, aqui, pelo formato HTML5.

Portanto, não temos entre os livros físicos e digitais uma continuidade linear, como se o material pudesse aos poucos ser convertido para o imaterial. O processo de produção de ambos pode ser radicalmente distinto, e a constituição de obra digital pode conter recursos inexistentes na forma tradicional. Grande diferença também existe no processo de leitura, que se pauta por atividades distintas: a narrativa do livro físico demanda um tipo de espaço, de concentração e de contato com a obra que gera uma experiência particular. Enquanto a leitura digital fornece a possibilidade de estímulos e interações diferenciadas com o leitor. O texto "apresentado sobre a tela, exige uma leitura vertical; a própria postura corporal do leitor é modificada; além disso, necessita-se de um aplicativo." (CALDIN; BLATTMANN, 2020, p. 688). Os meios coexistem, mas requerem mudanças radicais e uma especial atenção para a cadeia de produção de conteúdos e ambiente em que podem ser acessados.

O fato de não começarmos o processo de livros digitais com os professores faz com que as ferramentas viabilizadas pelo HTML5 sejam subaproveitadas. Essa limitação chega ao ponto de ser questionado o caráter efetivamente digital de uma obra em que nem o autor nem a editora têm conhecimentos sobre as possibilidades digitais para sua elaboração. Segundo Wilson Troque, essa lacuna faz com que algumas potencialidades do livro digital ainda demorem algum tempo para aparecer. A questão da capacidade de retenção da atenção, por exemplo, é um dos aspectos que podem ser trabalhados no formato do livro digital.

A possibilidade de coletar informações, por meio de testes e relatórios, para o próprio aperfeiçoamento da obra também ainda é um potencial não explorado. Os livros digitais podem gerar registros que embasam análises por parte de editoras e autores. Dessa forma, um retorno preciso sobre quais são as questões que mais contribuíram para o processo de aprendizagem, por exemplo, ou quais foram os tópicos que apresentaram maior interesse por parte dos estudantes, podem ser avaliados. Atualmente esse retorno é avaliado em percepções pouco precisas. "É 
totalmente empírico, pouquíssimo científico. É da experiência de um autor ou de um editor. E hoje se tem muitas formas de conseguir que essa informação venha de forma mais estruturada para melhorar a qualidade dos conteúdos". (TROQUE, 2021, n.p.).

Dado este panorama, temos que o livro didático digital ainda se encontra em um patamar bastante primário e seu uso requer o desenvolvimento de habilidades e conhecimentos por parte não só dos professores e estudantes envolvidos, mas também de outros agentes da cadeia produtiva. A princípio, a capacitação de autores para conhecimento sobre as possibilidades do formato digital se apresenta como indispensável para um efetivo aproveitamento dos recursos possíveis.

\section{VANTAGENS E LIMITAÇÕES DA IMATERIALIDADE DOS CONTEÚDOS DIDÁTICOS}

Considerando os diferentes formatos, destaca-se aqui algumas vantagens dos livros digitais, assim como suas limitações. Aspectos negativos do livro impresso podem se referir aos estudantes: o acúmulo de peso na mochila, a dificuldade de manipulação do volume de livros ou a necessidade de disponibilidade material para consulta das obras, que depende de bibliotecas ou complexos sistemas de distribuição. Para além da escola, considera-se a quantidade de papel envolvida na produção, tinta para impressão e recursos logísticos necessários para entrega dos livros às escolas.

Sob essa perspectiva, os livros digitais têm soluções mais práticas, podem acessar obras em um volume inestimável sem ocupar mais peso ou volume. Porém, no contexto brasileiro, temos uma estrutura precária de acesso à internet e problemas sérios quanto a dispositivos em que esse acesso possa se dar. Mesmo que o governo brasileiro se coloque como catalisador da difusão tecnológica, ainda não há um cenário que permita contar com a utilização de notebooks, leitores digitais ou celulares eficazes em todo o território nacional.

Considerando questões mais específicas à elaboração dos livros didáticos, Di Giorgi et al. (2014), levanta a questão da reutilização do livro didático por escolas públicas, como parte do PNLD. Segundo os autores, a permanência do livro com o aluno poderia ser mais contributiva em termos de capital cultural. Ainda que o processo de distribuição dos livros de maneira definitiva, sem devolução por parte dos alunos fosse custoso, "seria um investimento de alto retorno em termos de qualidade da Educação e de sua democratização". Nesse sentido, a disponibilização do conteúdo por parte virtual pode ser um potente contribuinte. $\mathrm{O}$ acesso permitido ao livro digital não precisa ser encerrado no momento de término do curso vigente. A disponibilização de um conteúdo para partes interessadas gera pouco ou zero custo uma vez que o material já está formulado para oferta digital (RIFKIN, 2016). Tratando-se ainda do propósito democrático, princípio universal da escola pública, os livros digitais poderiam ser disponibilizados abertamente para toda a população interessada.

Nesse sentido, o aspecto imaterial do conteúdo digital converte-se em valor, pois todo conhecimento passível de formalização pode ser abstraído do seu suporte material e humano, multiplicado quase sem custos na forma de conteúdos e utilizado ilimitadamente em máquinas padronizadas. Quanto mais ele se propaga, mais útil é a sociedade, tornando-se um bem comum acessível a todos, como nos ensina Gorz (2005) no clássico O Imaterial: Conhecimento, Valor e Capital.

Ou seja, ao passar conhecimento e conteúdos didáticos para o meio digital, não se diminui o estoque e não se priva seus autores dele. Um aspecto que constitui um terremoto epistemológico para a atividade econômica, baseadas na otimização da alocação de recursos escassos (DOWBOR,2020). Assim, pode-se prever que essa passagem para um suporte digital, que acessa conteúdos imateriais mostrará vantagens, tanto quanto provocará tanto resistências.

\section{APROXIMANDO CONTEÚDO E TECNOLOGIA E CONECTANDO TODOS OS ATORES ENVOLVIDOS}

Como vimos, há um uma cadeia bem estabelecida de produção de conteúdos didáticos que tem como um dos seus produtos, o livro didático físico. A partir de entrevistas com profissionais da área, sabe-se que temos um modelo 
de produção de conteúdo restrito a 200 autores e um número bastante superior de editores, criando um grupo de por volta de 3000 profissionais que produz e edita esse conteúdo, de forma autônoma ou sediado em organizações como editoras, grupos educacionais e escolas.

Majoritariamente a experiência desses profissionais se deu em aulas presenciais e na autoria e edição de livros físicos. De forma geral, uma experiência permeada pelas apostilas dos cursinhos pré-vestibular, que capacitaram professores a organizar pacotes de conteúdo que tinham como diretriz o acesso ao ensino superior.

Esses pacotes de conteúdo, na forma de sistemas de ensino, se tornaram muito usados tanto na rede privada, como pública. Associados a marcas escolares bem avaliadas, trazem o conteúdo educacional já organizado em aulas, cadernos de exercícios e avaliações, tanto para alunos como para professores. É possível imaginar as dificuldades da transposição desse conteúdo didático padronizado e geralmente impresso, durante a emergência gerada pela pandemia. Mesmo que muitos desses sistemas já usassem formatos e plataformas digitais para a interação, entrega e recepção destas atividades.

Mesmo que marcos legais como o BNCC (Base Nacional Curricular), estejam sendo sucessivamente implantados, parametrizando currículos da Educação Infantil ao Ensino Médio e propondo mudanças, a maior tarefa desses autores e editores de livros didáticos são ciclos de reaproveitamento e atualização de conteúdos que alimentam toda essa cadeia e mantém uma continuidade do atual modelo pedagógico. Assim, não há como não reconhecer que o PNLD de 2023, que ao trazer essa obrigatoriedade de uma versão digital de todos os livros produzidos, que deve produzir uma demanda efetiva de introdução de tecnologia digital e desafiar toda essa cadeia. Exigindo de autores e editores, uma abordagem mais contemporânea de conteúdos didáticos, próxima de um letramento digital já presente nos alunos.

Como vimos, uma solução bem-sucedida foi a adoção de planos locais que respeitassem limites e potências de cada território, colocando uma lista de opções à disposição das escolas. Essa estrutura já está presente na Guia de Implantação do PNLD 2023, apontando para o respeito a diversas culturas e suas diferentes condições tecnológicas. Ao mesmo tempo, pode-se dizer que a atuação em rede destas mesmas escolas deve ser fortalecida, tanto no sentido do suporte, como na circulação de informações.

O segundo aspecto crítico, observado durante a pandemia é o papel e a necessidade formação de professores. Nesse caso, além dessa formação tecnológica ser mais bem orquestrada, aproveitando rede já dinamizadas, há a possibilidade de incluir a colaboração de professores para criação e modulação de conteúdos. Se há um fortalecimento de ações em rede é possível que professores, autores e editores estejam mais conectados.

Quanto ao alunado, vimos a necessidade de formar habilidades e atitude que sustentem um ensino híbrido, tanto no sentido da construção de responsabilidades e autonomia, como da flexibilização de horários, grades curriculares e suportes. Ou seja, através de uma rede mais consolidada e em sinergia com conteúdos didáticos, reflexões e experiências sobre como estudar mais digitalmente estarão circulando, inclusive incluídos nas avaliações e percepções de como esse processo se dá tanto coletiva, como individualmente. O livro digital, etapa intermediária, para uma real inclusão de tecnologia digital na educação deve gerar um corpus de informações sobre seu uso e desempenho dos alunos, bastante diferente do que tivemos até agora para embasar decisões sobre conteúdos, modulações e currículos.

\section{CONCLUSÃO}

Percorrendo esse trajeto, que busca articular a experiência da pandemia com as questões e vantagens da passagem do livro didático para suportes imateriais, foi necessário percorrer temas muito diferentes. Assim, construiu-se um painel sobre o qual pudemos aprender a partir de uma implementação apressada, emergencial, mas efetiva, e passear por diferentes vivências, todas marcadas pelo mesmo fenômeno.

Ao historiarmos o percurso das transformações desta mesma passagem, tendo como parâmetro a magnitude e poder sobre seus atores, como o PNLD, tudo se ralenta. E revela como essas mudanças realmente ocorrem em escalas locais e globais. Essa distância de tempos e percepções, acaba sendo muito útil para compreender como 
unir disparidades tão grandes e nos coloca na condição de fazer prognósticos, projetar futuros, mesmo que prazo e resultados com certeza nos escapem. Porém, esperamos que esse exercício pode ser aproveitado por pesquisadores e interessados no assunto, criando observar e moldar essa inevitável transformação.

Em vista de futuras pesquisas, demonstram-se relevantes três pontos que este estudo identificou como críticos para o rumo dos livros didáticos no contexto digital do Brasil: 1) a questão da infraestrutura nacional, e da necessidade de haver políticas de inclusão digital compatíveis com o contexto local; 2) a capacitação dos envolvidos para além dos docentes, especialmente tratando-se dos agentes primeiros da cadeia produtiva: autores e editores; e 3) a consideração sobre a forma de estudo dos estudantes, a destaque da autonomia requerida para retenção da atenção.

Os três pontos críticos ocorrem dentro de uma problemática que se fez presente durante todo o estudo: a reflexividade do analógico sobre o digital. Primeiramente, o movimento pode ser compreendido nas práticas de aula, que levam ao ensino remoto estratégias que se mostraram insuficientes de contribuir para uma aprendizagem eficaz no meio digital. Em seguida, foi constatado como o livro digital também perde potencialidades quando restrito à replicação de um desenvolvimento projetado para o meio físico. O ambiente digital abre possibilidades distintas, que foram impulsionadas no contexto da pandemia, como se pôde conferir, em um sentido técnico; todavia, tal impulso deve ser acompanhado por políticas mais amplas que trabalhem lacunas aqui mencionadas, no intuito de que as novas utilizações possam de fato serem concebidas como novas, e não como versões adaptadas de um contexto anterior.

\section{REFERÊNCIAS BIBLIOGRÁFICAS}

ABED. Pesquisa sobre ensino remoto na Educação Básica. 22 jun. 2020. Disponível em: <http://www.abed.org.br/ site/pt/midiateca/noticias_ead/1775/2020/06/pesquisa_sobre_ensino_remoto_na_educacao_basica.>. Acesso em: 30 jun. 2021.

ALMEIDA, F. G. (org.). Vozes da aula (recurso eletrônico) :vida e pandemia. São Paulo EDUC, 2020. recurso online. Disponível em: < e-book https://www.pucsp.br/educ/livro?id=534>. Acesso em 23 jun. 2021.

BENEDITO, S. V. C.; CASTRO FILHO, P. J. (2020) A educação básica cearense em época de pandemia de coronavírus (covid-19): perspectivas e desafios no cenário educacional brasileiro. Rev. Nova Paideia -Revista Interdisciplinar em Educação e Pesquisa Brasília/DF, v. 2, n. 3. n. Esp. p. 58 - 71 - ISSN 2674-5976 DOI: 10.36732/riep. v2i3.58

Livros HTML5: Como adaptamos um livro digital? [S. I.: s. n.], 2020. 1 vídeo (3:10 min). Publicado pelo canal BLINKLEARNING. Disponível em: <https://www.youtube.com/watch?v=efeHUdjmKvk>. Acesso em: 24 jun. 2021.

BLINKLEARNING. Sobre nós. Página da web. Disponível em: <https://www.blinklearning.com/>. Acesso em: 24 jun. 2021.

BRASIL. Dez curiosidades sobre o mercado de didáticos brasileiro. Banco Nacional do Desenvolvimento (BNDES). 27 fev. 2018. Disponível em: <https://www.bndes.gov.br/wps/portal/site/home/conhecimento/noticias/noticia/ livro-didatico>. Acesso em: 26 jun. 2021.

BRASIL. Edital de convocação n 01/2021 - CGPLI. Edital de convocação para o processo de inscrição e avaliação de obras didáticas, literárias e pedagógicas para o Programa Nacional do Livro e do Material Didático - PNLD 2023. Ministério da Educação, 2021. Disponível em: <https://www.fnde.gov.br/index.php/centrais-de-conteudos/publicacoes/category/165-editais?download=14530:edital-2023>. Acesso em: 29 jun. 2021.

BRASIL. Fundo Nacional de Desenvolvimento da Educação (FNDE). Ministério da Educação: Brasília, DF, $2017 a$. 
Histórico. Disponível em: <http://www.fnde.gov.br/component/k2/item/518-hist\%C3\%B3rico>. Acesso em: 29 jun. 2021.

BRASIL. Fundo Nacional de Desenvolvimento da Educação (FNDE). Ministério da Educação: Brasília, DF, 2017b. Programas do Livro. Disponível em: <https://www.fnde.gov.br/index.php/programas/programas-do-livro/legislacao/ item/9787-sobre-os-programas-do-livro>. Acesso em: 29 jun. 2021.

CALDIN, C. F.; BLATTMANN, U. Letramento digital: e-books interativos para crianças. ÁGORA, Florianópolis, v. 30, n. 61, p. 679-702, jul./dez. 2020.

CETIC, 2019. TIC Domicílios 2019, principais resultados. CGI.br/NIC.br, Centro Regional de Estudos para o Desenvolvimento da Sociedade da Informação (Cetic.br), São Paulo, 2020. Disponível em: <https://cetic.br/media/ analises/tic_domicilios_2019_coletiva_imprensa.pdf>. Acesso em: 15 abr. 2021.

DI GIORGI, C. A. G. et al. Uma proposta de aperfeiçoamento do PNLD como política pública: o livro didático como capital cultural do aluno/família. Ensaio: aval. pol. públ. Educ., Rio de Janeiro, v.22, n. 85, p. 1027-1056, out./dez. 2014.

DOWBOR, L. O capitalismo se desloca: novas arquiteturas sociais. Edições SESC: São Paulo, 2020.

GATTI, B. Possível reconfiguração dos modelos educacionais pós-pandemia. Estudos Avançados, v. 34, n. 100, 2020.

Gomes, M. F. V. B. et al. Ensino remoto emergencial no contexto da pandemia da Covid - 19: trabalho e formação do professor de geografia no Paraná. Revista Pegada, v. 21, n.3. 323 set./dez. 2020.

GORZ, A. O Imaterial: conhecimento, valor e capital. Annablume: São Paulo, 2005.

IBGE. Pesquisa nacional por amostras de domicílios contínua - PNAD Contínua, 2018. Disponível em:/<https:// www.ibge.gov.br/estatisticas/sociais/trabalho/17270-pnad-continua.html?=\&t=o-que-e>, Acesso: 10 jun. 2021.

IIVARI, N.; SHARMA, S.; VENTÄ-OLKKONEN L. Digital transformation of everyday life - How COVID-19 pandemic transformed the basic education of the young generation and why information management research should care? International Journal of Information Management, v. 55, 102183, 2020.

MARINELLI, L; KOIKE, B.; TECCHIO M. (2020) Grandes negócios redefinem forças na educação básica. 8/03/2020 Valor Econômico, Globo, G1, São Paulo. Disponível em: <https://valor.globo.com/empresas/noticia/2021/03/08/ grandes-negocios-redefinem-forcas-na-educacao-basica.ghtml>. Acesso em: 23 jun. 2021.

MELLO, G.; NYKO, D.; GARAVINI, F.; ZENDRON, P. Tendências da era digital na cadeia produtiva do livro. Banco Nacional de Desenvolvimento Econômico e Social: BNDES Setorial 43, Rio de Janeiro, p. 41-79. 2016. Disponível em: <https://web.bndes.gov.br/bib/jspui/bitstream/1408/9583/2/BS\%2043\%20Tend\%c3\%aancias\%20da\%20 era\%20digital\%20na\%20cadeia\%20produtiva\%20do\%20livro_P_BD.pdf>. Acesso em: 26 jun. 2021.

NIELSEN: Conteúdo Digital do Setor Editorial Brasileiro. Câmara Brasileira do Livro (CBL) /Sindicato Nacional dos Editores de Livros (SNEL)/Nielsen, 2020a. Disponível em: <https://snel.org.br/wp/wp-content/uploads/2020/06/ Produ\%C3\%A7\%C3\%A3o_e_Vendas_2019_imprensa_.pdf>. Acesso em: 26 jun. 2021. 
NIELSEN: Produção e Vendas do Setor Editorial Brasileiro. Câmara Brasileira do Livro (CBL)/Sindicato Nacional dos Editores de Livros (SNEL)/Nielsen, 2020b. Disponível em: <https://snel.org.br/wp/wp-content/uploads/2020/06/ Produ\%C3\%A7\%C3\%A3o_e_Vendas_2019_imprensa_.pdf>. Acesso em: 26 jun. 2021.

PORTILLO PEÑUELAS, S. A.; REYNOSO GONZÁLEZ, O. U.; CASTELLANOS PIERRA, L. I. El inicio de un nuevo ciclo escolar en México ante el Covid-19. Comparativo entre contextos rural y urbano. Revista Conrado, v. 16, n. 77, p. 218-228. 2020.

PRENSKY, M. Teaching Digital Natives. Partnering for real learning. Oaks, California: Corwin Publishers, 2010.

RAD CAMAYD, Y.; ESPINOZA FREIRE, E. E. (2021). Covid-19 um desafio para a educação básica. Revista Conrado, v. 17, n. 78 , p. $145-152$.

RIFKIN, J. (2016) Sociedade com custo marginal zero. M. Books do Brasil Editora Ltda.

RNP. Descritivo de tecnologias. Rede Nacional de Ensino e Pesquisa: (relatório online), 2021b. Disponível em: <https://www.gov.br/fnde/pt-br/acesso-a-informacao/acoes-e-programas/programas/programas-do-livro/consultas-editais/editais/edital-pnld-2023-1/RNP_DescritivosdeTecnologias_v2.pdf>. Acesso em: 29 jun. 2021.

RNP. Relatório recomendatório sobre oferta de livros digitais pelo Programa Nacional de Livros Didáticos (PNLD). Rede Nacional de Ensino e Pesquisa: (relatório online), 2021a. Disponível em: <https://www.gov.br/ fnde/pt-br/acesso-a-informacao/acoes-e-programas/programas/programas-do-livro/consultas-editais/editais/edital-pnld-2023-1/PNLDDIG_Rel_de_recomendacoes_v3_2020.pdf>. Acesso em: 29 jun. 2021.

SNEL. Senso do livro digital. Ano Base 2016. Câmara Brasileira do Livro (CBL) /Sindicato Nacional dos Editores de Livros (SNEL)/Fundação Instituto de Pesquisas Econômicas (FIPE), 2017. Disponível em: <https://snel.org.br/ wp/wp-content/uploads/2018/02/Apresentacao-Censo-do-Livro-Digital.pdf>. Acesso em: 26 jun. 2021.

TROQUE, W. A. Entrevista concedida aos autores para elaboração do artigo. Do livro didático físico ao imaterial: o empurrão da pandemia. Vídeo, 1h08, 21 jun. 2021.

UNICEF. COVID-19: Are children able to continue learning during school closures? Disponível em: <https://www. unicef.org/brazil/media/10006/file/remote-learning-factsheet.pdf>. Acesso em: 30 jun. 2021.

VAHL, M. M; PERES, E. O programa do livro didático para o ensino fundamental (1971-1976). Cadernos de Pesquisa, v.47, n.164, p.562-585, abr./jun. 2017. Disponível em: <https://www.scielo.br/j/cp/a/CRjQnLQx9Stp3QXxjXR Gdmw/?lang=pt\&format=pdf>. Acesso em: 29 jun. 2021.

VAHL, M. M; PERES. As disputas editoriais no campo do programa do livro didático para o ensino fundamental do instituto nacional do livro - plidef/inl (1971-1976). Hist. Educ. (Online) Porto Alegre, v. 20 n. 50 p. 219-24. set./ dez., 2016. Disponível em: <https://www.scielo.br/j/heduc/a/LgrSbGHZWMvG5bSJpqn4pMK/?lang=pt\&format=p df>. Acesso em: 29 jun. 2021.

VALLEJOS SALAZAR, G. A.; GUEVARA VALLEJOS, C. A. (2021). Educación en tiempos de pandemia: una revisión bibliográfica. Revista Conrado, v. 17, n. 80, p. 166-171. 